\title{
ALL ON 4 VERSUS ALL ON 6 IMPLANT CONCEPTS FOR REHABILITATION OF EDENTULOUS MAXILLA. SHORT TERM RANDOMIZED CLINICAL AND RADIOGRAPHIC STUDY
}

\author{
Shahinaz Sayed Mohamed Hassan* and Amr Abd El Bary Mahdy Emarah**
}

\begin{abstract}
Purpose: The aim of the present study was to evaluate clinical and radiological outcomes of "All on 4" Versus "All on 6" implant concepts for rehabilitation of edentulous maxilla.

Materials and methods: 10 patients with complete maxillary edentulism and distal extension mandibular ridges who had resorption in the posterior aspects of the maxillary ridge were randomly assigned into 2 groups: Group 1 included 5 patients who received All on four maxillary prosthesis, and group 2 included 5 patients who received All on six maxillary prosthesis. Four (group 1) or six (group 2) implants were inserted between the maxillary sinuses and immediately loaded by provisional acrylic dentures. Definite screw retained porcelain fused to metal fixed prosthesis were inserted after 6 months. Plaque index, gingival index, probing depth, implant stability, and peri-implant bone loss were measured for both groups at base line (after insertion), 6 months and 12 months after insertion.
\end{abstract}

Results: The survival rate was $85 \%$ and $100 \%$ for group 1 and group 2 respectively. Plaque and gingival scores significantly increased with time in group 1 only. At 6 and 12 months, group 1 showed significant higher plaque and gingival scores than group 2. Pocket depth and implant stability increased significantly with time in both groups. Group 1 showed significant higher pocket depth and reduced implant stability than group 2 at all observations. Bone resorption significantly increased after 12 months compared to 6 months in both groups. Group 1 recorded significant higher bone loss than group 2 after 6 and 12 months of prosthesis delivery.

Conclusion: Within the limitations of this study, it could be concluded that All on 6 implant concept is recommended for restoration of atrophied maxilla compared to All on 4 implant concept as it was associated with improved clinical and radiographic parameters after one year.

* Lecturer, Department of Removable Prosthodontics, Faculty of Dentistry, Beni-Suef University, Egypt.

** Lecturer, Department of Removable Prosthodontics, Faculty of Dentistry, Fayoum University, Egypt. 


\section{INTRODUCTION}

Implant restoration in edentulous maxilla is usually challenging than mandible due to vertical and horizontal alveolar bone resorption and compromised bone quality, especially in the posterior region of the maxillary arch, where bone grafting is often indicated due to maxillary sinus pneumatization $^{1}$. Other challenges include; fine trabecular bone which may subjects the maxilla to higher biomechanical forces ${ }^{2}$, thicker gingiva is usually associated with increased abutment height and consequently increase vertical lever $\mathrm{arm}^{3}$. Furthermore, immediate loading of implants during the healing period leads to bone over load which may exceed physiologic threshold ${ }^{4}$ due to lower mechanical anchorage. The insufficient posterior bone may be managed with long distal cantilever prosthesis or use of sinus lift procedures ${ }^{5}$. The use of long cantilevers increase stress to the posterior implants and increase implant failures due to biomechanical complications ${ }^{6}$. Sinus lift procedures requires multiple surgical procedures which increase patient morbidity, and involves greater risk of complications, a longer rehabilitation period, higher costs and low patient satisfaction ${ }^{7}$.

The use of implant tilting in the maxilla has been demonstrated to be an alternative to bone grafting ${ }^{8-10}$. By tilting the distal implants, a more posterior implant position can be reached, and improved implant anchorage can be achieved by benefiting from the cortical bone of the wall of the sinus ${ }^{11}$. The "All on four" implant concept involves insertion of 2 implants anterior to the sinus wall with $30^{\circ}$ tilting posteriorly and anterior axial implants in the cuspid or lateral incisor region, then immediately loading of these implants with fixed provisional restoration till osseointegration of the implants occur. The use of this concept was reported by Malo et al. ${ }^{11,12}$ a viable treatment alternative for atrophied maxilla. This concept has several advantages as longer implants may be placed, implant-to-bone contact area and primary implant stability may be increased, more posterior implant position can be achieved by distal implant tilting thus reducing the cantilever, and provide improved implant anchorage ${ }^{10}$. Moreover, favorable load distribution for full-arch prostheses can be achieved with "cornerstones implants": two posterior and two anterior and well spread implants. 13 The use of bone grafts is avoided, resulting in significantly less morbidity and dramatically lower financial costs. Furthermore, the immediate function concept with immediate screw-retained prosthesis provides cost effective, time-saving treatments and achieves immediate function and esthetics ${ }^{14}$

Although All on four concept for edentulous mandible achieves high success rate, Browaeys et $\mathrm{al}^{15}$ showed significantly lower implant success after 1 year in maxilla (56\%) compared with the mandible $(90 \%)$ when implants were immediately loaded with an All-on-4 full-arch screw-retained prosthetic bridge. Moreover, the oral hygiene of the hybrid All on four fixed restoration is challenging due to presence of extensive prosthetic flanges which induce more plaque accumulation ${ }^{16}$. Therefore, the maximum use of the residual bone anatomy should be considered to customize the proper implant number, position, and improve success of dental restoration ${ }^{17}$. As an alternative to the conventional All on four implant concept, Agliardi and colleagues ${ }^{17}$ reported that six implants could be considered a predictable and cost- and time-effective option for the immediate restoration of the edentulous maxilla, avoiding bone grafting procedures. Accordingly, the aim of the present investigation was to evaluate the success rate, clinical and radiologic results of "All on 4" and "All on 6" implant concepts for rehabilitation of atrophied edentulous maxilla. The null hypothesis was that there will be no difference in clinical and radiologic results between the 2 design concepts after one year. 


\section{MATERIALS AND METHODS}

\section{Patient selection}

This trial was conducted on 10 patients ( 5 males and 5 females) with complete maxillary edentulism and distal extension mandibular ridges. The patients complained from lack of retention and stability of their maxillary dentures and need a fixed prothesis. The inclusion criteria include: 1) ridge resorption in the posterior aspects of the maxillary ridge that preclude insertion of dental implants due to maxillary sinus pneumatization, 2) sufficient bone quantity and quality between maxillary sinuses to receive 4 or 6 implants of at least $12 \mathrm{~mm}$ length and $3.6 \mathrm{~mm}$ in width (this was detected by using cone beam computerized tomography). The exclusion criteria were: 1) blood disorders, 2) autoimmune diseases, 3) uncontrolled diabetes mellitus, 4) metabolic diseases affecting bone, 5) irradiation of the head or neck region in the last 2 years, 6) inadequate oral hygiene performance, and 7) smoking habit. The patients instructed about the treatment protocol and objectives prior to obtain an informed consent. The study was conducted according the ethical principles of Helsinki Declaration (https://www. wma.net/) and approved by the faculty ethical committee (No. \#FDBSUREC/21012020/MS). The patients were categorized by age, gender, and bone height in the maxillary anterior region and were randomly assigned into 2 groups using balanced randomization, then comparison of baseline criteria between groups was made to ensure that there was no difference in age, gender, and bone height between groups to avoid selection bias. Group 1 included 5 patients who received All on four maxillary screw retained fixed prosthesis, and group II included 5 patients who received All on six maxillary retained fixed prosthesis

\section{Surgical and prosthetic interventions}

For all included subjects, new maxillary complete denture and mandibular distal extension partial dentures were fabricated and worn for 3 months to allow neuromuscular adaptation before implant installation. Gutta perchae markers were added to the palatal and buccal surfaces of the maxillary dentures. The dual scan protocol was used. Each participant underwent a cone beam computerized tomography scan (CBCT, i- CAT Vision ${ }^{\circledR}$, Imaging Sciences International, Hatfield, PA, USA) while the patient wearing the dentures with the radiopaque gutta perchae markers. Another CBCT scan of the denture a lone was made. The data were overlapped using the accompanying software (OnDemand V3) and the reformatted images were used to produce 3D image of each jaw. The implants were virtually placed according to the "All on four" implant protocol (Group 1) or All on six implant protocol $^{1,18}$. For All on 4 group, anterior implants were placed in the canine/lateral incisor area and posterior implants were distally tilted $30^{\circ}$ from the vertical plane (anterior to the maxillary sinuses). This arrangement allows shorten cantilever length as it increased the anteroposterior spread $^{10}$. For All on 6 group, posterior implants were inserted just anterior to the maxillary sinuses and inclined 30 degree distally and 2 implants were inserted in central incisor areas and 2 implants in the canine areas. Using the soft-ware, drilling sleeves were positioned over each implant orifice. A mucosal supported stereolithographic surgical guide (fig1)

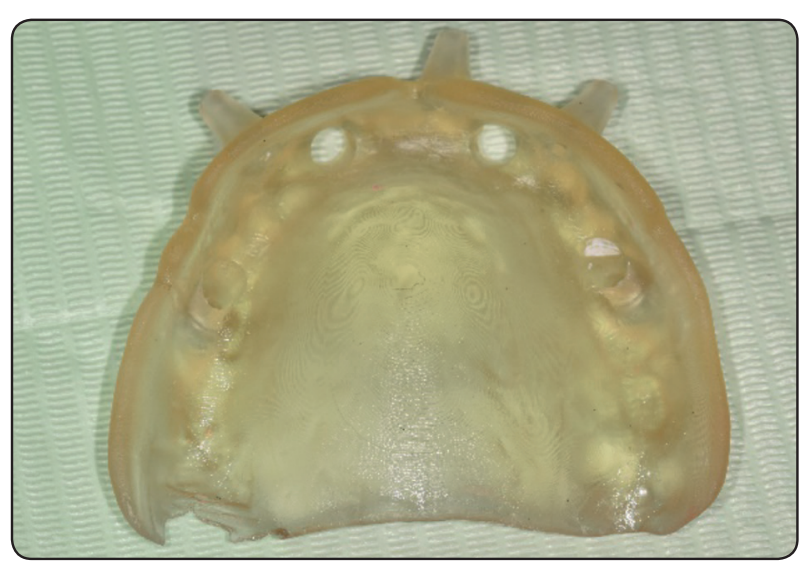

Fig. (1) Mucosal supported stereolithographic surgical guide constructed using rapid prototyping technology 
was constructed using rapid prototyping technology (In2Guide) and used for flapless drilling and placement of the implants.

Four (group I) or six (group II) implants (Dentium, Super Line, South Korea) were inserted using the surgical guide and the universal surgical kit (In2Guide, Universal Kit Cybermed Inc) supplied with the mucosal supported stereolithographic surgical template to be used during osteotomy preparation (fig 2).

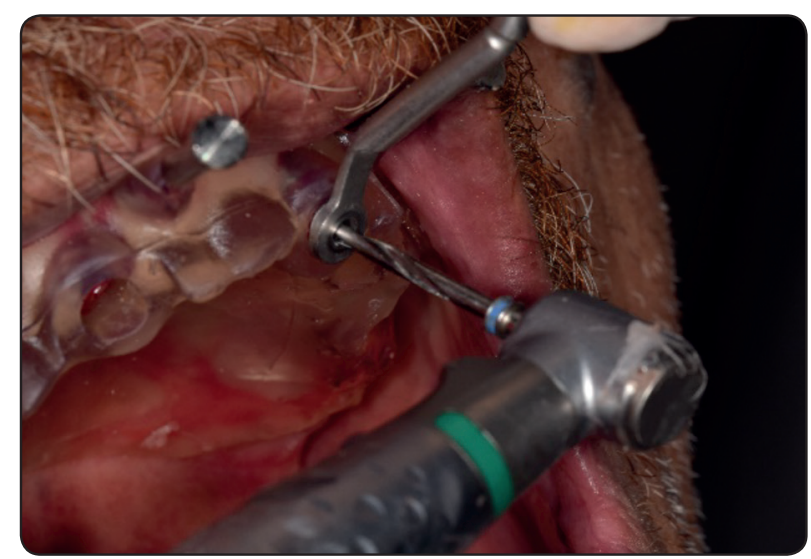

Fig. (2) Flapless implant placement using the universal surgical kit

This kit includes hand drill sleeves that fit the template sleeves with successive diameters. The template was stabilized in the patient's mouth by anchor pins. The minimum torque at implant placement was $40 \mathrm{Ncm}$ to permit immediate loading of the implants. If the bone had a reduced density during drilling, the last drill was omitted to obtain adequate primary stability. 25 degree angled multiunit abutments were connected to the posterior inclined implants to correct the implant inclinations and straight or 15 degree angled multiunit abutments were connected to the anterior and canine implants to correct the implant inclination due to labial angulation of premaxillary bone. Titanium caps were connected to the multiunit abutments. The denture was connected to the titanium caps using self-cure acrylic resin while the patients occluded in centric occlusion. The maxillary dentures were hollowed over the abutments, then the denture was modified by removal of the palatal portion and used as a provisional restoration for immediate loading of the implants ${ }^{19}$

The second molar teeth were removed and first molar teeth were relived from the occlusion to avoid premature occlusal loading on the inclined distal implants. Postoperative medications include; Antibiotics (amoxicillin $625 \mathrm{mg}+$ clavulanic acid $125 \mathrm{mg}$, Augmentin ${ }^{\circledR}$ 1gm), Corticosteroids (Dexamethazone $\left.{ }^{\circledR}\right)$ injection immediately after surgery to reduce postoperative edema and inflammation. Anti-inflammatory medication (ibuprofen ${ }^{\circledR}, 600 \mathrm{mg}$ ) was administered for 5 days postoperatively. Analgesics (Ketolac $₫ 10 \mathrm{mg}$ ) were given on the day of surgery and postoperatively for the first 5 days. Participants were informed to eat soft diet and avoid hard foods. Participants were instructed for oral hygiene procedures and informed to attend regular follow-up visits to verify oral hygiene practice and perform adjustments of the dentures till osseointegration occurs.

After 6 months of osseointegration, abutment level open tray impression procedure was started. The provisional acrylic denture was un-screwed from the multi-unit abutments. Primary impression of the upper jaw was made using irreversible hydrocolloid impression material and poured. Custom acrylic tray was constructed. The abutment level long transfer copings were screwed to the multi-unit abutment and splinted with Duralay (Duralay, Reliance Dental MFG Co, Worth, IL, USA) acrylic resin to prevent movement of the transfer coping during impression procedure. Light body rubber base impression (SPEEDEX, Coltene/Whaledent Pvt., Ltd., 9450 Alstalten, Switzerland) was injected around the transfer coping. The tray was filled with heavy body impression material and seated. The copings were unthreaded and the impression was removed from patient mouth. Abutment analogues were 


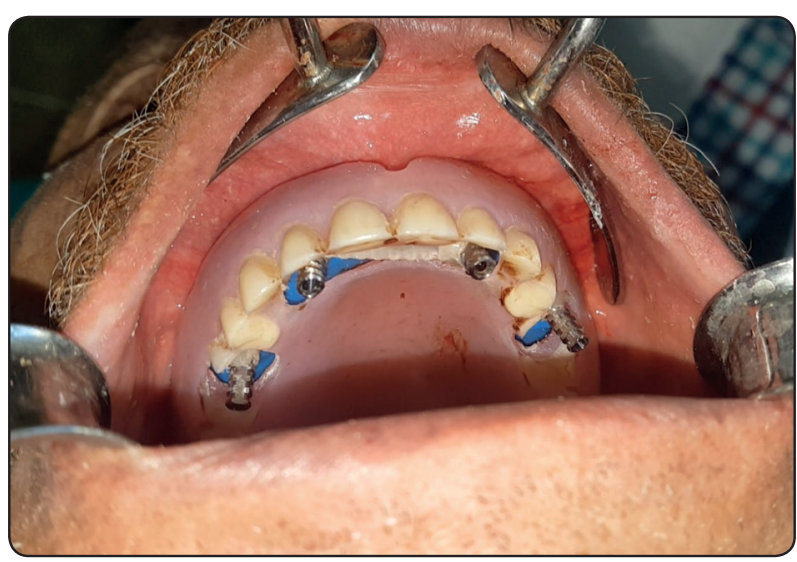

Fig. (3) Immediate loading of the implants using maxillary denture as a provisional acrylic prosthesis

screwed to the transfer coping and the impression was poured to obtain master cast. Plastic caps of multiunit abutments were screwed to the abutment analogues on the master cast. Record blocks were fabricated on the casts and used to record jaw relationship. Appropriate lip support was restored. The cast was scanned using a CAD/CAM device (Ceramill Map400, Amann Girrbach AG. Koblach, Austria), then a fixed prosthesis was designed using the software of the device with 12 teeth in both groups for standardization purposes (the second molars were omitted and prosthesis was extended to the first molars only). The fixed prosthesis pattern was printed by prototyping using a castable resin (Duralay, Reliance Dental MFG Co, Worth, IL, USA), then tried in patient mouth. The resin bar pattern was invested, cast with Cobalt chromium alloy (Wironit, BEGO Bremer Goldschlägerei Wilh. Herbst GmbH, Germany), tried in patient mouth for passivity using single screw test. The porcelain powder (VITA Zahnfabrik, Bad Säckingen, Germany) was mixed with the modeling liquid, applied onto the metal over the opaque layer, fired, finished and glazed. Fixed prostheses were delivered to all patients and panoramic radiographs were made to ensure passive seating of the prosthesis for group I (fig 4) and group 2 (fig 5).

\section{Evaluation of clinical and radiologic outcomes}

Clinical and radiographic evaluations of periimplant tissues were performed after prosthesis delivery (T0), six months (T6) and 12 months (T12) after delivery. Plaque index and gingival index were evaluated using the Mombelli indices ${ }^{20}$. A graduated plastic probe was used to measure the pocket depth in $\mathrm{mm}^{21,22}$.

Implant mobility was assessed using resonance frequency analysis. The Osstell device (Integration Diagnostics Ltd.) expresses the mobility as implant stability quotient. The multiunit abutments were removed and smart pigs of the Ostell device were connected to the internal hex of the implants. Plaque index, gingival index and probing depth were measured at the mid-facial, mid-lingual, mid-mesial, and mid-distal aspects of each fixture.
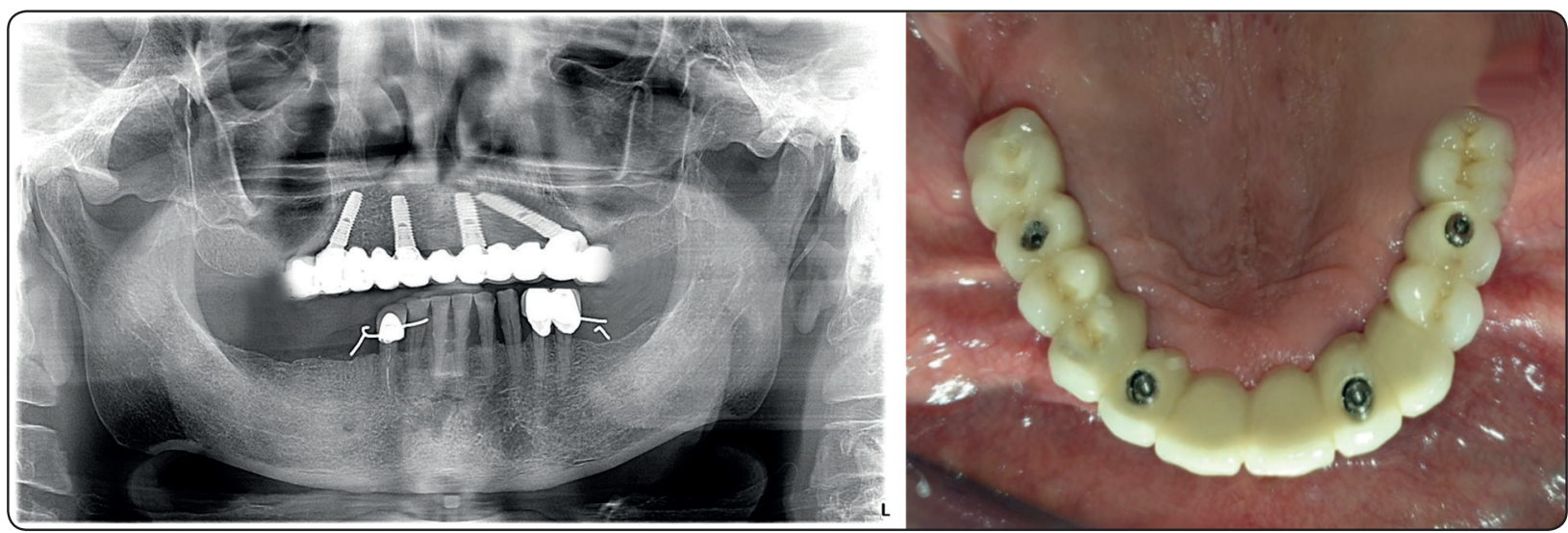

Fig. (4) Group I; A, panoramic radiographs at prosthesis delivery, B, intraoral view of the All on four fixed screw retained prosthesis 

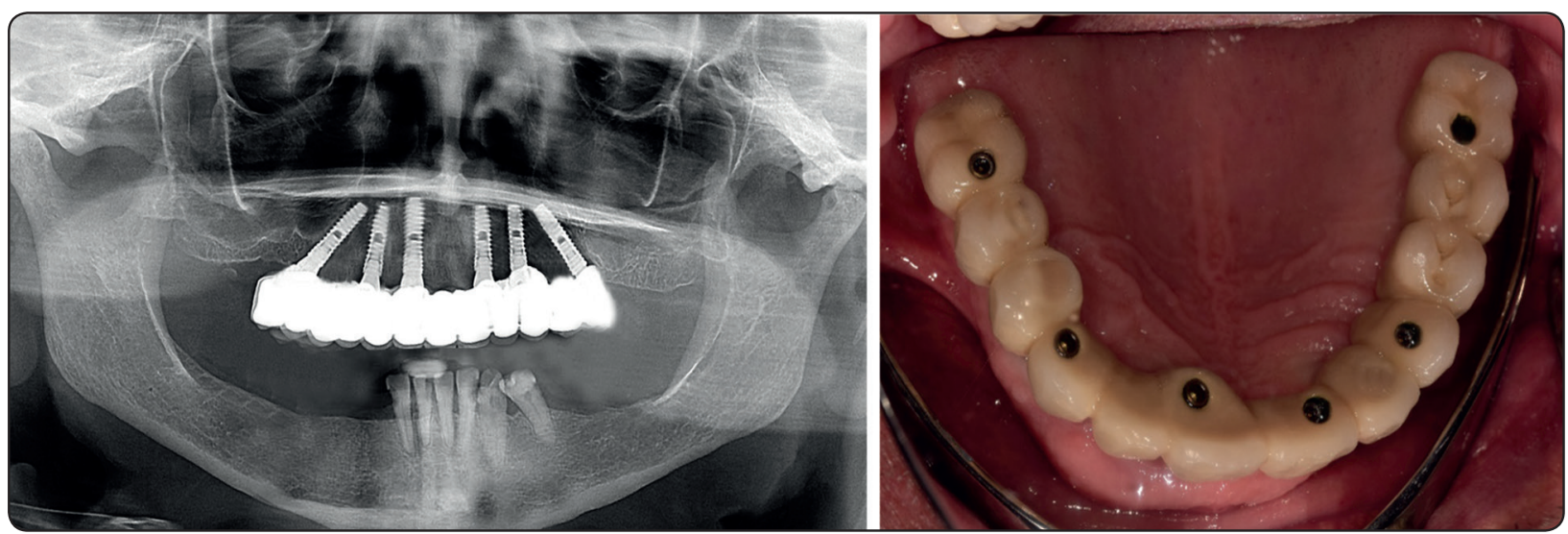

Fig 5. Group II; A, panoramic radiographs at prosthesis delivery, B, intraoral view of the All on six fixed screw retained prosthesis

For each participant, Cone beam computerized tomography (i-CAT device; Imaging Sciences Intl) was made at base line, 6 months $(6 \mathrm{~m})$, and 12 months $(12 \mathrm{~m})$ after denture delivery. The marginal bone resorption was measured at mesial, distal, buccal and lingual surface of each implant using the software (OnDemand3DApp Software; CyberMed Inc) of the CBCT in the panoramic and crosssectional images. Mesial, distal, buccal, and lingual bone loss were averaged and the mean was subjected to statistical analysis. Distance from implant abutment junction (point A) to the bone contact with implant (point B) was measured to give bone level. Bone loss was calculated by subtracting bone levels at $6 \mathrm{~m}$ and $12 \mathrm{~m}$ from bone levels at base line. The measurements were performed on the patient level, ie, right and left measurements for all implants were averaged. To test the inter-examiner reliability, 3 different examiners perform the measurement. To test the intra-examiner reliability one observer performed the measurements at 3 different times on the same day of measurements.

\section{Statistical analysis}

Data was analyzed with SPSS program version 25 Statistical Packages for Social Science (SPSS Inc., Chicago, IL, USA). The data was non-parametric as verified by Shapiro Wilk Test. To reduce the risk of measurement bias, Alpha Cronbach test was used to test the inter-examiner and the intra-examiner reliability of the measurements and the data were reliable if correlation coefficient was $>.80$. The data were presented as median (minimum-maximum). Friedman test was used to compare different observation times within groups, and Wilcoxon signed ranks test was used to compare between each two times. For between-group comparisons, the non-parametric Mann- Whitney test was used. The threshold for statistical significance was set at $\mathrm{P}<.05$.

\section{RESULTS}

Correlation coefficient for tested parameters are presented in table 1 . All coefficients were $>.80$, this means that all measurements were reliable. 20 implants were inserted in group 1 and 30 implants were inserted in group 2. Three implants in the same patients ( 2 posterior and one anterior) were failed in group 1 resulting in $85 \%$ survival rate in this group. No implants failed in group 2 resulting in $100 \%$ survival rate in this group. Group 2 recorded significant higher survival rate than group 1 (log rank test, $\mathrm{p}=.030)$. The failed implants were associated with bone loss, suppuration and mobility. The patient (in group 1) was excluded from the study without affecting the results since intention to treat analysis was followed in this clinical trial. 
Comparison of plaque scores, gingival scores, pocket depth, implant stability, and bone loss between groups and time intervals is presented in table 2. Plaque and gingival scores significantly increased with time in group 1, however in group 2 , there was no significant difference in plaque and gingival scores between observation times. Multiple comparison of plaque and gingival scores between each 2 observation times was performed using Wilcoxon signed ranks test and presented in the same table. At base line, no difference in plaque and gingival scores was noted between groups. At 6 and 12 months, group 1 showed significant higher plaque and gingival scores than group 2. Pocket depth increased significantly with time in both groups. There was a significant difference in pocket depth between each 2 observation times. Group 1 showed significant higher pocket depth than group2 at base line and after 6 and 12 months. For both groups, implant stability significantly increased after 6 months compared to base line. However, no significant difference in implant stability between 6 months and 12 months was noted. Group 2 showed significant higher implant stability than group 1 at different observation times.

For group 1, the median peri-implant bone loss was .93 and $1.23 \mathrm{~mm}$ after 6 and 12 months respectively. For group 2, the median peri-implant bone loss was .72 and $.92 \mathrm{~mm}$ after 6 and 12 months respectively. Bone resorption significantly increased after 12 months compared to 6 months in both groups. Group 1 recorded significant higher bone loss than group 2 after 6 and 12 months of prosthesis delivery.

TABLE (1) Correlation coefficient for tested parameters to test the inter-examiner and intra-examiner reliability of the measured data

\begin{tabular}{|c|c|c|c|c|c|c|}
\hline Investigator no & Group & plaque & gingival & pocket & stability & bone \\
\hline \multirow[t]{2}{*}{1 vs. 2} & All on 4 & $.8924 *$ & $.9154 *$ & $.8864 *$ & $.9416^{*}$ & $.9135 *$ \\
\hline & All on 6 & $.8854 *$ & $.9087 *$ & $.8754 *$ & $.9546^{*}$ & $.9254 *$ \\
\hline \multirow[t]{2}{*}{2 vs. 3} & All on 4 & $.9078 *$ & $.9021 *$ & $.8923 *$ & $.9715^{*}$ & $.9313 *$ \\
\hline & All on 6 & $.9097 *$ & $.9113 *$ & $.9128 *$ & $.9664 *$ & $.9479 *$ \\
\hline \multirow[t]{2}{*}{1 vs. 3} & All on 4 & $.9512 *$ & $.9008 *$ & $.9248^{*}$ & $.9848^{*}$ & $.9550 *$ \\
\hline & All on 6 & $.8945^{*}$ & $.9113^{*}$ & $.9346^{*}$ & $.9748^{*}$ & $.9114 *$ \\
\hline \multirow[t]{2}{*}{1 vs. 1} & All on 4 & $.9133 *$ & $.8586^{*}$ & $.9179 *$ & $.9441 *$ & $.9009^{*}$ \\
\hline & All on 6 & $.9465^{*}$ & $.8881 *$ & $.9449 *$ & $.9576^{*}$ & $.9129 *$ \\
\hline
\end{tabular}


TABLE (2) Comparison of plaque scores, gingival scores, pocket depth, implant stability, and bone loss between groups and time intervals

\begin{tabular}{|c|c|c|c|c|}
\hline & $\begin{array}{l}\text { Base line } \\
\text { (T0) }\end{array}$ & $\begin{array}{l}6 \text { months } \\
\text { (T6) }\end{array}$ & $\begin{array}{l}12 \text { months } \\
\text { (T12) }\end{array}$ & $\begin{array}{l}\text { Freidman test } \\
\quad \text { (p value) }\end{array}$ \\
\hline \multicolumn{5}{|c|}{ Plaque scores } \\
\hline $\begin{array}{c}\text { All on } 4 \\
\text { group } \mathrm{M}(\mathrm{mi}-\mathrm{ma})\end{array}$ & $.0(.00-.5) \mathrm{a}$ & $1.5(1.0-2.0) \mathrm{b}$ & $2.5(1.75-3.0) \mathrm{c}$ & $.001 *$ \\
\hline $\begin{array}{c}\text { All on } 6 \\
\text { group } M(m i-m a)\end{array}$ & $.0(.00-.5) \mathrm{a}$ & $.5(.00-1.0) \mathrm{a}$ & $.75(.00-1.0) \mathrm{a}$ & .52 \\
\hline Mann-Whitney test (p value) & 1.00 & $.015^{*}$ & $.020 *$ & \\
\hline \multicolumn{5}{|c|}{ Gingival scores } \\
\hline $\begin{array}{c}\text { All on } 4 \\
\text { group } M(m i-m a)\end{array}$ & $.0(.00-0.5) \mathrm{a}$ & $1.0(.00-1.0) \mathrm{b}$ & $1.50(.00-1.0) \mathrm{c}$ & $.023 *$ \\
\hline $\begin{array}{c}\text { All on } 6 \\
\text { group } M(m i-m a)\end{array}$ & $.0(.00-0.5) \mathrm{a}$ & $0.5(.00-1.0) \mathrm{a}$ & $0.5(.00-3.0) \mathrm{a}$ & .064 \\
\hline Mann-Whitney test (p value) & 1.00 & $.042 *$ & $.024 *$ & \\
\hline \multicolumn{5}{|c|}{ Pocket depth } \\
\hline $\begin{array}{c}\text { All on } 4 \\
\text { group } M(m i-m a)\end{array}$ & $.85(.25-1.5) \mathrm{a}$ & $2.0(1.5-2.5) b$ & $3.0(2.25-3.5) \mathrm{c}$ & $.018 *$ \\
\hline $\begin{array}{c}\text { All on } 6 \\
\text { group } M(m i-m a)\end{array}$ & $.80(.25-1.25) \mathrm{a}$ & $1.5(1.0-2.0) \mathrm{b}$ & $1.9(1.5-2.25) \mathrm{c}$ & $.027 *$ \\
\hline Mann-Whitney test (p value) & $.045^{*}$ & $.022 *$ & $.004 *$ & \\
\hline \multicolumn{5}{|c|}{ Fixture stability } \\
\hline $\begin{array}{c}\text { All on } 4 \\
\text { group } M(m i-m a)\end{array}$ & $60(58-62) a$ & $62(60-63) b$ & $63(60-64) b$ & $.041 *$ \\
\hline $\begin{array}{c}\text { All on } 6 \\
\text { group } M(\mathrm{mi}-\mathrm{ma})\end{array}$ & $67(65-70) a$ & $69(67-71) b$ & $70(68-72) b$ & $.039 *$ \\
\hline Mann-Whitney test (p value) & $.021 *$ & $.022 *$ & $.010^{*}$ & \\
\hline \multicolumn{5}{|c|}{ Bone resorption } \\
\hline $\begin{array}{c}\text { All on } 4 \\
\text { group } \mathrm{M}(\mathrm{mi}-\mathrm{ma})\end{array}$ & - & $.93(.6-1.1) \mathrm{a}$ & $1.23(.8-1.4) \mathrm{b}$ & $.025^{*}$ \\
\hline $\begin{array}{c}\text { All on } 6 \\
\text { group } M(m i-m a)\end{array}$ & - & $.72(.5-9.0) \mathrm{a}$ & $.92(.61-1.0) \mathrm{b}$ & $.030 *$ \\
\hline Mann-Whitney test ( $p$ value) & - & $.017 *$ & $.012 *$ & \\
\hline
\end{tabular}

M: median, mi: minimum, ma: maximum, *: p value significant at .05. Different letters in the same raw indicate significant difference between observation times (Wilcoxon signed ranks test, $p<.05$ ). Same letters indicate no difference between time intervals (Wilcoxon signed ranks test, $p>.05$ ). 


\section{DISCUSSION}

The flapless surgical approach was used in this study as it has several advantages including; minimal post-operative discomfort, reduced edema, and facilitate immediate prosthetic loading with provisional dentures (no sutures or open wound) ${ }^{23}$, ${ }^{24}$. Moreover, the flapless approach reduced the peri-implant bone loss as reflection of the flap cause mucoperiosteal stripping that may induce bone loss around the implants ${ }^{25}$. Stereolithographic surgical stent together with CBCT was used for proper data transfer of the surgical field and for implant placement.

This template allows accurate 3-dimentional placement of the implants in planned implant position. The conventional stent and the 2-dimensional panoramic radiographs are not capable for accurate visualization of bone and vital structure position in buccolingual dimension. ${ }^{26}$

Cone beam computerized tomography (CBCT) was used for evaluation of marginal bone resorption as it provides information on bone loss on buccal and lingual aspects of the implants as well as mesial and distal aspects due to its three-dimensional nature. In contrast, Periapical radiography are 2 dimensional only. Moreover, CBCT, can be used easily especially elevated floor of the mouth without causing patient discomfort as periapical radiographs do. CBCT also has no magnification or distortion as panoramic radiographs ${ }^{27}, 28$. The use of CBCT in measuring bone resorption around implants was recommended by other investigators ${ }^{29,30}$.

The results of this study showed significant higher failure rate of the implant in group I (15\%) compared to group II $(0 \%)$. This could be attributed to the reduced number of the implants in All on four group which increased load transmission to the implants especially with immediate loading protocol. This may endanger the implants in the critical healing period especially with reduced bone quality of the maxillary ridges. A similar observation was noted by
Browaeys et $\mathrm{al}^{15}$ who found lower implant success after 1 year in maxilla (56\%) compared with the mandible $(90 \%)$ when implants were immediately loaded with an All-on-4 full-arch screw-retained prosthetic bridge. In contrast to our finding, Other authors $^{17}$ showed no significant difference in implant survival rate between All on four and All on six groups. The difference between the results could be attributed to the opposing arch dentition. In this study, the opposing arch contain lower anterior teeth which may transmit increased occlusal loads to the maxillary arches due to differnce in properioception and increased habitual biting ${ }^{31}$. Another explanation of reduced survival rate in All on four group could be attributed to the presence of cantilevers in most of cases (frist molar cantilevered), while in All on 6 group, no cantilevers were added. The presence of cantilever increases the risk of biomechanical complications $^{32}$ such as implant overload, and prosthetic screw loosening. Therfore, whenever bone volume present in the maxilla, the insertion of more implants is beneficial to improve prosthetic support and to decrease cantilever length ${ }^{32}$

The plaque and gingival scores increased significantly with time in all on 4 group, and the increase in plaque was insignificant for all on 6 group. Also, All on 4 group showed significant higher plaque and gingival scores than All on 6 group. This may be due to complicated oral hygiene of the hybrid All on four fixed restoration due to presence of extensive prosthetic flanges which induce more plaque accumulation ${ }^{16}$. Moreover, the presence of cantilever in All on 4 group and increased spaces between the implants enhance plaque stagnation and make cleansing more difficult. The increased plaque with time may be due to oral hygiene practice of the patients was insufficient despite the instructions given. The increased plaque accumulation usually increases gingival inflammation and could be responsible for increased gingival index. In line with our results, Elsyad et al..$^{33}$ in a recent study, showed increased plaque accumulation in All on 
four fixed implant restoration compared to milled bar overdentures and attributed this increase to the inability of the patients to remove and clean the prosthesis compared to milled bar overdentures. In contrast, another author ${ }^{34}$ showed a decrease in plaque scores for fixed restoration supported by four implants after 7-year evaluation period.

The pocket depth increased significantly with time in both groups. This could be attributed to the increased bone loss in both groups with time together with gingival enlargement of thick maxillary mucosa. The increased pocket depth also may be due to submerging of the inclined implants below the crestal bone to avoid protrusion of the mesial portion of the implants above the bone. This may increase pocket depth especially at distal aspects of these implants. In line with this finding, several investigators noted increased probing depth around implants supporting "All on four" fixed restorations ${ }^{35,36}$. Pocket depth in group 1 was higher than in group 2 at all observations, and even at base line. This could be due to increase bone loss and gingival inflammation in group 1 compared to group 2. This bone loss occurred in the first six months and could be responsible for increasing pocket depth measurement at base line.

Implant stability significantly increase from base line to 6 months then insignificantly increased at 12 months. A similar observation was noted for All on 6 implants supporting maxillary prosthesis ${ }^{37}$. The authors noted that mean periotest values decreased, and implant stability quotient increased significantly after the first 3 months for tilted and axial implants. The increased stability of implants with time in both groups may reflect the increased bone to implant contact at the interface after bone remodeling and maturation process of osseointegration ${ }^{38}$. At all observation times implant stability of group 2 was higher than group 1 . The lower bone density of maxillary ridge, and the reduced number of the implants in group 1 may subject the implants in this group to higher biomechanical load which may decrease percentage of bone to implant contact and decrease implant stability. In contrast, wide implant distribution in the group 2 may cause physiologic loading of the bone, thus increasing the implant stability.

For both prosthesis bone loss ranged from $.72 \mathrm{~mm} 1.23 \mathrm{~mm}$ after 12 months. This range still located in the normal values reported earlier ${ }^{39,}{ }^{40}$. Bone loss increased with time for both prostheses. A similar observation was noted in another study ${ }^{36}$ for all on 4 mandibular fixed restoration and may be due to bone reaction to surgical trauma and occlusal load. All on four group showed significant higher bone loss than All on 6 group after 6 and 12 months. This could be attributed to several reasons. The long spans created by the all on 4 prosthesis compared to short spans created by all on 6 ones make the prosthesis is more susceptible to deformation and bending during occlusal forces. Thus, higher stresses are transmitted to the implants and could be responsible for increasing bone loss. On the other side, the all on 6 creates stiffer framework which is less susceptible to deformation. Moreover, the presence of cantilever even it was short (first molar only) may transmit increased overload for implantsupport system especially the distal implants ${ }^{41}$. Furthermore, the presence of more implants in all on 6 group allows better load distribution and transmission of force to the implants and supporting tissues compared to all on 4 group $^{41}$. Also increased plaque accumulation and gingival inflammation in all on four group may contribute to increase in bone loss. These explanations, are in agreement with another invitro study ${ }^{42}$ in which the author found that the all-on-six concept appears to induce lower stress compared to the all-on-four concept. In contrast, Tallarico et al. ${ }^{17}$ found no difference in bone loss between All-on-4 (1.71 $10.42 \mathrm{~mm}$ ) and All-on-6 (1.51 $10.36 \mathrm{~mm})$ after 5 years.

The study limitations are the reduced patient cohort and the short follow-up period. Also, the measurement of clinical and radiographic parameters were not performed in the critical healing period (in the first 6 months after implant installation). 


\section{CONCLUSION}

Within the limitations of this study, it could be concluded that all on 6 implant concept is recommended for restoration of atrophied maxilla compared to All on 4 implant concept as it was associated with improved clinical and radiographic parameters after one year.

\section{REFERENCES}

1. Malo P, de Araujo Nobre M, Lopes A, Francischone C, Rigolizzo M. "All-on-4” immediate-function concept for completely edentulous maxillae: a clinical report on the medium (3 years) and long-term (5 years) outcomes. Clin Implant Dent Relat Res. 2012;14 Suppl 1:e139-50.

2. Rodriguez AM, Orenstein IH, Morris HF, Ochi S. Survival of various implant-supported prosthesis designs following 36 months of clinical function. Ann Periodontol. 2000;5:101-8.

3. Bergendal T, Engquist B. Implant-supported overdentures: a longitudinal prospective study. Int J Oral Maxillofac Implants. 1998;13:253-62.

4. Jofre J, Cendoya P, Munoz P. Effect of splinting mini-implants on marginal bone loss: a biomechanical model and clinical randomized study with mandibular overdentures. Int J Oral Maxillofac Implants. 2010;25:1137-44.

5. Patzelt SB, Bahat O, Reynolds MA, Strub JR. The all-onfour treatment concept: a systematic review. Clin Implant Dent Relat Res. 2014;16:836-55.

6. Horita S, Sugiura T, Yamamoto K, Murakami K, Imai Y, Kirita T. Biomechanical analysis of immediately loaded implants according to the "All-on-Four" concept. J Prosthodont Res. 2017;61:123-32.

7. Schwartz-Arad D, Herzberg R, Dolev E. The prevalence of surgical complications of the sinus graft procedure and their impact on implant survival. J Periodontol. 2004;75:511-6.

8. Aparicio C, Perales P, Rangert B. Tilted implants as an alternative to maxillary sinus grafting: a clinical, radiologic, and periotest study. Clin Implant Dent Relat Res. 2001;3:39-49.

9. Fortin Y, Sullivan RM, Rangert BR. The Marius implant bridge: surgical and prosthetic rehabilitation for the completely edentulous upper jaw with moderate to severe resorption: a 5-year retrospective clinical study. Clin Implant Dent Relat Res. 2002;4:69-77.
10. Krekmanov L, Kahn M, Rangert B, Lindstrom H. Tilting of posterior mandibular and maxillary implants for improved prosthesis support. Int J Oral Maxillofac Implants. 2000;15:405-14.

11. Malo P, Rangert B, Nobre M. All-on-4 immediate-function concept with Branemark System implants for completely edentulous maxillae: a 1-year retrospective clinical study. Clin Implant Dent Relat Res. 2005;7 Suppl 1:S88-94.

12. Malo P, Rangert B, Nobre M. "All-on-Four" immediatefunction concept with Branemark System implants for completely edentulous mandibles: a retrospective clinical study. Clin Implant Dent Relat Res. 2003;5 Suppl 1:2-9.

13. Duyck J, Van Oosterwyck H, Vander Sloten J, De Cooman M, Puers R, Naert I. Magnitude and distribution of occlusal forces on oral implants supporting fixed prostheses: an in vivo study. Clin Oral Implants Res. 2000;11:465-75.

14. Sannino G, Bollero P, Barlattani A, Gherlone E. A Retrospective 2-Year Clinical Study of Immediate Prosthetic Rehabilitation of Edentulous Jaws with Four Implants and Prefabricated Bars. J Prosthodont. 2017;26:387-94.

15. Browaeys H, Dierens M, Ruyffelaert C, Matthijs C, De Bruyn H, Vandeweghe S. Ongoing Crestal Bone Loss around Implants Subjected to Computer-Guided Flapless Surgery and Immediate Loading Using the All-on-4(R) Concept. Clin Implant Dent Relat Res. 2015;17:831-43.

16. Abi Nader S, Eimar H, Momani M, Shang K, Daniel NG, Tamimi F. Plaque Accumulation Beneath Maxillary Allon-4 Implant-Supported Prostheses. Clin Implant Dent Relat Res. 2015;17:932-7.

17. Agliardi EL, Pozzi A, Stappert CF, Benzi R, Romeo D, Gherlone E. Immediate fixed rehabilitation of the edentulous maxilla: a prospective clinical and radiological study after 3 years of loading. Clin Implant Dent Relat Res. 2014;16:292-302.

18. Malo P, Friberg B, Polizzi G, Gualini F, Vighagen T, Rangert B. Immediate and early function of Branemark System implants placed in the esthetic zone: a 1-year prospective clinical multicenter study. Clin Implant Dent Relat Res. 2003;5 Suppl 1:37-46.

19. ELsyad M, Elgamal M, Askar O,Al-Tonbary G. Patient satisfaction and oral health-related quality of life (OHRQoL) of conventional denture, fixed prosthesis and milled bar overdenture for All-on-4 implant rehabilitation. A crossover study. Clin Oral Implants Res. 2019;30:1107-17.

20. Mombelli A, van Oosten MA, Schurch E, Jr., Land NP. The microbiota associated with successful or failing osseointegrated titanium implants. Oral Microbiol Immunol. 1987;2:145-51. 
21. Elsyad MA, Elsaih EA, Khairallah AS. Marginal bone resorption around immediate and delayed loaded implants supporting a locator-retained mandibular overdenture. A 1-year randomised controlled trial. J Oral Rehabil. 2014;41:608-18.

22. Elsyad MA, Mahanna FF, Elshahat MA, Elshoukouki AH. Locators versus magnetic attachment effect on periimplant tissue health of immediate loaded two implants retaining a mandibular overdenture: a 1-year randomised trial. J Oral Rehabil. 2016;43:297-305.

23. Campelo LD, Camara JR. Flapless implant surgery: a 10year clinical retrospective analysis. Int J Oral Maxillofac Implants. 2002;17:271-6.

24. Elsyad MA. A new surgical template with a handpiece positioner for use during flapless placement of four dental implants to retain a mandibular overdenture. J Prosthodont. 2012;21:573-7.

25. Caneva M, Botticelli D, Salata LA, Souza SL, Bressan E, Lang NP. Flap vs. "flapless" surgical approach at immediate implants: a histomorphometric study in dogs. Clin Oral Implants Res. 2010;21:1314-9.

26. Lal K, White GS, Morea DN, Wright RF. Use of stereolithographic templates for surgical and prosthodontic implant planning and placement. Part II. A clinical report. J Prosthodont. 2006;15:117-22.

27. Naitoh M, Hayashi H, Tsukamoto N, Ariji E. Labial bone assessment surrounding dental implant using cone-beam computed tomography: an in vitro study. Clin Oral Implants Res. 2012;23:970-4.

28. Raes F, Renckens L, Aps J, Cosyn J, De Bruyn H. Reliability of circumferential bone level assessment around single implants in healed ridges and extraction sockets using cone beam CT. Clin Implant Dent Relat Res. 2013;15:661-72.

29. Razavi T, Palmer RM, Davies J, Wilson R, Palmer PJ. Accuracy of measuring the cortical bone thickness adjacent to dental implants using cone beam computed tomography. Clin Oral Implants Res. 2010;21:718-25.

30. Elsyad MA, Khirallah AS. Circumferential bone loss around splinted and nonsplinted immediately loaded implants retaining mandibular overdentures: A randomized controlled clinical trial using cone beam computed tomography. J Prosthet Dent. 2016;116 741-8

31. .Abd El-Dayem MA, Assad AS, Abdel-Ghany MM. The effect of different mandibular dentures on antagonistic maxillary ridge. Implant Dent. 2007;16:421-9.

32. Malo P, Nobre M, Lopes A. The rehabilitation of completely edentulous maxillae with different degrees of resorption with four or more immediately loaded implants: a 5-year retrospective study and a new classification. Eur J Oral Implantol. 2011;4:227-43.

33. ELsyad MA, Alameldeen HE, Elsaih EA. Four-implantsupported fixed prosthesis and milled bar overdentures for rehabilitation of the edentulous mandible: A 1-year randomized controlled clinical and radiographic study. Int J Oral Maxillofac Implants. 2019;34:1493-503.

34. Ayub KV, Ayub EA, Lins do Valle A, Bonfante G, Pegoraro T, Fernando L. Seven-Year Follow-up of Full-Arch Prostheses Supported by Four Implants: A Prospective Study. The International journal of oral \& maxillofacial implants. 2017;32:1351-8.

35. Ayna M, Gulses A, Acil Y. A comparative study on 7-year results of "All-on-Four" immediate-function concept for completely edentulous mandibles: metal-ceramic vs. barretained superstructures. Odontology. 2018;106:73-82.

36. Krennmair S, Weinländer M, Malek M, Forstner T, Krennmair G, Stimmelmayr M. Mandibular Full-Arch Fixed Prostheses Supported on 4 Implants with Either Axial Or Tilted Distal Implants: A 3-Year Prospective Study. Clin Implant Dent Relat Res. 2016;18:1119-33.

37. Wentaschek S, Hartmann S, Walter C, Wagner W. Six-implant-supported immediate fixed rehabilitation of atrophic edentulous maxillae with tilted distal implants. Int J Implant Dent. 2017;3:35.

38. Balshi SF, Allen FD, Wolfinger GJ, Balshi TJ. A resonance frequency analysis assessment of maxillary and mandibular immediately loaded implants. The International journal of oral \& maxillofacial implants. 2005;20:584-94.

39. Albrektsson T, Zarb G, Worthington P, Eriksson AR. The long-term efficacy of currently used dental implants: a review and proposed criteria of success. Int J Oral Maxillofac Implants. 1986;1:11-25.

40. Zarb GA, Albrektsson T. Consensus report: towards optimized treatment outcomes for dental implants. J Prosthet Dent. 1998;80:641.

41. Bhering CL, Mesquita MF, Kemmoku DT, Noritomi PY, Consani RL, Barao VA. Comparison between all-on-four and all-on-six treatment concepts and framework material on stress distribution in atrophic maxilla: A prototyping guided 3D-FEA study. Mater Sci Eng C Mater Biol Appl. 2016;69:715-25.

42. Almeida EO, Rocha EP, Freitas Junior AC, Anchieta RB, Poveda R, Gupta N, et al. Tilted and short implants supporting fixed prosthesis in an atrophic maxilla: a 3D-FEA biomechanical evaluation. Clin Implant Dent Relat Res. 2015;17 Suppl 1:e332-42. 